\title{
Promoção à saúde e prevenção de acidentes na infância: uma ação de estudantes de medicina
}

\section{Health promotion and accident prevention in childhood: an intervention of medical students}

\author{
Danielle Bivanco-Lima ${ }^{1,2}$, Juliana de Carvalho Moura ${ }^{1,2}$, Silvia Helena Nogueira Tirico ${ }^{3}$, \\ Marcela Rufino Mazzeo ${ }^{3}$, Mateus Trinconi Cunha ${ }^{3}$, Rodrigo Armando Sperandio ${ }^{3}$, \\ Maya Silberfeld, Maria Carolina Simone ${ }^{3}$, Stephanie Bibikoff ${ }^{3}$, Elaine Fracasso Tambellini ${ }^{4}$, \\ Cássio Silveira ${ }^{5}$, Regina Maria Giffoni Marsiglia ${ }^{5}$
}

Bivanco-Lima D, Moura JC, Tirico SHN, Mazzeo MR, Cunha MT, Sperandio RA, Silberfeld M, Simone MC, Bibikoff S, Tambellini EF, Marsiglia RMG. Promoção à saúde e prevenção de acidentes na infância: uma ação de estudantes de medicina / Health promotion and accident prevention in childhood: an intervention of medical students.Rev Med (São Paulo). 2013 abr.-jun.;92(2):119-27.

\begin{abstract}
RESUMO: Introdução: A promoção à saúde é um grande desafio no Sistema Único de Saúde. A realização de ações de promoção faz parte das competências necessárias ao egresso do curso de medicina, segundo as Diretrizes Curriculares Nacionais para o Curso de Graduação em Medicina (DCN). Objetivo: Este trabalho visa descrever a elaboração e implementação de ação lúdica, visando educação em saúde com enfoque em prevenção de acidentes domésticos na infância, por parte de alunos do primeiro ano do curso de medicina da Faculdade de Ciências Médicas da Santa Casa de São Paulo (FCMSCSP). Métodos: O uso da metodologia da problematização conduziu a construção do projeto, desde o reconhecimento do território da Unidade Básica de Saúde (UBS), discussão de problemas encontrados, levantamento bibliográfico, elaboração de hipóteses de solução e implementação de ação. Resultados: Os alunos do primeiro ano de medicina optaram por trabalhar com o tema de prevenção de acidentes domésticos na infância, em parceria com a UBS e com organização não-governamental (ONG) da região, que realiza atividades educativas e de lazer com crianças em idade escolar, após o horário da aula. Os alunos construíram jogos discutindo a prevenção de acidentes e folheto explicativo para pais e responsáveis. Foi realizada gincana em novembro de 2012, em que os alunos coordenaram os jogos com as crianças que utilizam a ONG. Os alunos construíram narrativa sobre a percepção da atividade, com boa avaliação da ação. Discussão: Há evidências do benefício de inserir o aluno precocemente em ações na comunidade, principalmente na participação ativa de atividades de promoção à saúde, visando à aprendizagem significativa. A problematização é estratégia privilegiada de ensino do tema de promoção à saúde e à construção das competências necessárias à elaboração destas ações.
\end{abstract}

DESCRITORES: Educação médica; Promoção da saúde; Prevenção de acidentes; Acidentes domésticos/prevenção \& controle; Criança; Atividades de lazer; Mortalidade da criança.

\begin{abstract}
Introduction: Health promotion is a great challenge in the Brazilian National Health System. The implementation of health promotion actions is part of the necessary skills of medical school undergraduates, according to the National Curriculum Guidelines for Undergraduate Medicine (DCN). Objective: This study aims to describe the development and implementation of games, seeking health education focusing on prevention of domestic accidents in childhood, made by students of the first year of medical school, Faculty of Medical Sciences of Santa Casa de São Paulo (FCMSCSP). Methods: The methodology of problematization led to construction of the project, started with the recognition of the territory of primary care service, discussion of found problems, evaluation of medical literature, towards the formulation of possible solutions and implementing an prevention action. Results: The first year medical students have chosen to work with prevention of domestic accidents in childhood, in partnership with UBS and a nongovernmental organization in the region, which conducts educational and recreational activities with children, in the after-school period. The students put up games discussing accident prevention and a leaflet for parents and guardians. Tournament was held in November 2012, in which medical students coordinated games with the children. Students constructed narrative about their perception of activity, with good evaluation of the health promotion action. Discussion: There is evidence of the benefit of early introduction of medical students in the community context, especially in active participation of health promotion activities, aiming to meaningful learning. The problematization strategy is a privileged teaching method aiming actions of health promotion and building the necessary skills for the production of these actions.
\end{abstract}

KEYWORDS: Medical education; Health promotion; Accident prevention; Accidents, home/prevention \& control; Child; Leisure activities; Child mortality.

\footnotetext{
1. Médicas assistentes do Centro de Saúde Escola Barra Funda "Dr. Alexandre Vranjac".

2. Professoras da Disciplina de Higiologia do Curso de Medicina da Universidade Nove de Julho.

3. Acadêmicos de medicina da Faculdade de Ciências Médicas da Santa Casa de São Paulo.

4. Gerente de Unidade Básica de Saúde ligada a Irmandade da Santa Casa de Misericórdia de São Paulo.

5.Professores do Departamento de Medicina Social da Faculdade de Ciências Médicas da Santa Casa de São Paulo.

Endereço para correspondência: Danielle Bivanco-Lima. Faculdade de Ciências Médicas da Santa Casa de São Paulo (FCMSCSP). Rua Dr. Cesario Motta Jr, 61 - 5ªndar - Medicina Social (A/C Sara). CEP: 01221-020. E-mail: danielle.bivanco@gmail.com
} 


\section{INTRODUÇÃO}

realização de ações de promoção à saúde
configura-se como um dos grandes desafios
do Sistema Único de Saúde (SUS) na contemporaneidade. A promoção à saúde se constitui em compromisso do Estado Brasileiro em propiciar a todos os indivíduos e coletividades a participação efetiva nos processos decisórios voltados a construção de melhores condições de vida, estimulando a autonomia dos cidadãos ${ }^{1}$.

A elaboração de políticas públicas intersetoriais pautadas na "articulação de saberes técnicos e populares, na mobilização de recursos institucionais e comunitários, públicos e privados" consiste em uma audaciosa proposta que visa, sobretudo, a superação de práticas de saúde centradas na racionalidade biomédica, essencialmente curativistas e focadas no atendimento individual, onde preponderam os saberes técnico-científicos em detrimento dos saberes inerentes ao mundo-da-vida dos sujeitos ${ }^{2}$.

$\mathrm{Na}$ organização do sistema público de saúde brasileiro, a ações de promoção à saúde constituem um dos campos essenciais das ações de Atenção Primária. Portanto, a Unidade Básica de Saúde (UBS) é o contexto privilegiado de realização de atividades desta natureza, devido à proximidade física ao território sob seus cuidados, o que permite o reconhecimento das características demográficas de sua população, dos principais agravos e determinantes dos processos de saúde-doença, bem como das dinâmicas sociais e culturais das coletividades ${ }^{3}$.

Dentre os agravos que merecem destaque estão as causas externas, que englobam mortes por homicídios, acidentes e suicídios, e consistem em uma das mais importantes causas de morbimortalidade tanto no adulto, quanto na infância no Brasil. No Estado de São Paulo em 2010, evidenciou-se um total de 24.151 mortes por causas externas, sendo responsáveis por $9,12 \%$ do total de óbitos em todas as faixas etárias. As causas externas ocupam o quarto lugar dentre as principais causas de mortalidade do Estado de São Paulo, sendo superadas somente pelas doenças do aparelho circulatório $(30,17 \%)$, as neoplasias $(17,47 \%)$ e as doenças do aparelho respiratório $(12,4 \%)^{4}$.

Em 2010, os óbitos por causas externas ocupam o sexto lugar entre as principais causas de óbitos em crianças menores de um ano $(2,71 \%$ das mortes) no Estado, sendo que na faixa etária de um a quatro anos, estas ocupam o primeiro lugar entre as causas de morte (17,28\% das mortes) (Tabela 1).

TABELA 1. Importância de óbitos por causas externas (capítulo 20 do CID-10) no Estado de São Paulo de acordo com a faixa etária, em 2010)

\begin{tabular}{l|c|c|c}
\hline \multicolumn{1}{c|}{ Faixa etária } & $\begin{array}{l}\text { Posição de óbitos por } \\
\text { causas externas }\end{array}$ & $\begin{array}{l}\text { Número total de óbitos por } \\
\text { causas externas }\end{array}$ & $\begin{array}{l}\text { Porcentual do total de } \\
\text { óbitos por causas externas }\end{array}$ \\
\hline Menores de 1 ano & $6^{\circ}$ & 194 & $2,71 \%$ \\
1 a 4 anos & $1^{\circ}$ & 192 & $17,28 \%$ \\
5 a 14 anos & $1^{\circ}$ & 493 & $31,91 \%$ \\
15 a 24 anos & $1^{\circ}$ & 4450 & $65,07 \%$ \\
25 a 34 anos & $1^{\circ}$ & 5046 & $48,95 \%$ \\
35 a 44 anos & $1^{\circ}$ & 3824 & $24,51 \%$ \\
45 a 54 anos & $3^{\circ}$ & 3118 & $10,90 \%$ \\
55 a 64 anos & $7^{\circ}$ & 2142 & $5,28 \%$ \\
65 ou mais anos & $9^{\circ}$ & 4244 & $2,78 \%$ \\
\hline Total* & $4^{\circ}$ & 24151 & $9,12 \%$ \\
\hline
\end{tabular}

*O total não corresponde a soma das caselas acima da tabela pois há a inclusão de 448 óbitos ocorridos em indivíduos de idade desconhecida (devido ao mau preenchimento do atestado de óbito).

Fonte: Sistema de Informação de Mortalidade. Disponível em: http://www.datasus.gov.br.

No município de São Paulo, as causas externas acometem as crianças de maneira similar, embora se encontre na quarta posição entre as causas de óbito na faixa etária de 1 a 4 anos e se torna a principal causa de morte dos 5 aos 19 anos (Tabela 2). No município de São Paulo, no ano de 2010, as causas externas são responsáveis por $11,7 \%$ dos óbitos na faixa etária de 1 a 4 anos e são responsáveis por $23,3 \%$ dos óbitos de 5 a 9 anos, sendo que este percentual aumenta na adolescência. Dentre as causas externas, os acidentes são considerados a principal causa de óbito em todas as faixas etárias ${ }^{4}$. 
TABELA 2. Importância dos óbitos por causas externas (capítulo 20 do CID 10) no município de São Paulo, de acordo com a faixa etária, em 2010

\begin{tabular}{c|c|c|c}
\hline Faixa Etária & $\begin{array}{l}\text { Posição de óbitos por } \\
\text { causas externas }\end{array}$ & $\begin{array}{l}\text { Número total de óbitos } \\
\text { por causas externas }\end{array}$ & $\begin{array}{l}\text { Porcentual do total de } \\
\text { óbitos por causas externas }\end{array}$ \\
\hline Menores de 1 ano & $5^{\circ}$ & 72 & $3,58 \%$ \\
1 a 4 anos & $4^{\circ}$ & 34 & $11,68 \%$ \\
5 a 14 anos & $1^{\circ}$ & 125 & $32,72 \%$ \\
15 a 24 anos & $1^{\circ}$ & 1195 & $63,73 \%$ \\
25 a 34 anos & $1^{\circ}$ & 1223 & $47,06 \%$ \\
35 a 44 anos & $1^{\circ}$ & 948 & $24,03 \%$ \\
45 a 54 anos & $3^{\circ}$ & 800 & $10,78 \%$ \\
55 a 64 anos & $5^{\circ}$ & 561 & 5,36 \\
65 ou mais anos & $8^{\circ}$ & 1323 & $3,23 \%$ \\
\hline Total* & $4^{\circ}$ & 6417 & $9,15 \%$ \\
\hline
\end{tabular}

*O total não corresponde a soma das caselas acima da tabela pois há a inclusão de 136 óbitos ocorridos em indivíduos de idade desconhecida (devido ao mau preenchimento do atestado de óbito)

Fonte: Sistema de Informação de Mortalidade.Disponível em: http://www.datasus.gov.br

Os acidentes domésticos encontram-se como um dos principais motivos de óbitos em crianças nas faixas etárias menores, e geralmente estão relacionados a quedas, ingestão de produtos de limpeza, acidentes com objetos perfuro cortantes (como facas, garfos, tesouras), choque (tomadas desprotegidas) e afogamento. É importante ressaltar que os acidentes não letais são muito mais frequentes. Estima-se que para cada acidente com morte existam cerca de 45 que necessitem de internação hospitalar ${ }^{5}$. Em estudo de Unglert et al. ${ }^{6}$, realizado em dois postos de assistência médica do município de São Paulo, foram entrevistados 388 adultos que levaram crianças para atendimento médico e observouse que $99(25,5 \%)$ relataram algum acidente com as crianças nos dois anos anteriores.

Para o enfrentamento de um problema de tamanha magnitude, consideramos que os processos de imersão no território voltados ao reconhecimento e à compreensão das necessidades de saúde de indivíduos, famílias e comunidades constituem uma ação imprescindível para a construção de ações de promoção à saúde articuladas entre os diversos setores, grupos e membros da sociedade. As ações de promoção à saúde poderiam ser agrupadas em dois grandes grupos de atividades. O primeiro grupo de atividades se dirige "à transformação dos comportamentos dos indivíduos, focando nos seus estilos de vida e localizando-os no seio das famílias e, no máximo, no ambiente das 'culturas' da comunidade em que se encontram" " O segundo grupo de atividades de promoção à saúde estaria voltado "ao coletivo de indivíduos e ao ambiente (...) físico, social, político, econômico e cultural, através de políticas públicas e de ambientes favoráveis ao desenvolvimento da saúde e do reforço da capacidade dos indivíduos e das comunidades (empowerment)"?.
As Diretrizes Curriculares Nacionais do Curso de Graduação em Medicina (DCNs) explicitam claramente a necessidade de realizar atividades de promoção à saúde entre as competências gerais do egresso médico ${ }^{8}$, justificando a importância de realizar ações de promoção à saúde em disciplinas curriculares durante a graduação médica.

\section{OBJETIVO}

Tomando como referência a primeira perspectiva do conceito de promoção à saúde descrita por Buss ${ }^{7}$ optamos, no presente trabalho, pela elaboração de uma ação educativa lúdica, realizada pelos alunos do primeiro ano de Medicina da Faculdade de Ciências Médicas da Santa Casa de São Paulo (FCMSCSP), na disciplina de Ciências Sociais Aplicadas à Saúde, junto às crianças residentes em uma área de extrema vulnerabilidade social na região central do município de São Paulo com o objetivo de orientar sobre os riscos de acidentes domésticos na infância. Esta disciplina incorporou o estágio do Programa Nacional de Reorientação da Formação Profissional em Saúde (PRÓSAUDE) em unidades de Atenção Primária à Saúde na região central do município de São Paulo.

\section{METODOLOGIA}

Para a concretização deste trabalho, o reconhecimento do território e das necessidades de saúde de indivíduos, famílias e da comunidade pelos alunos de graduação, foi imprescindível para a construção de ações de promoção à saúde articuladas entre os diversos setores, grupos e membros da sociedade. Diante desta perspectiva, os alunos do primeiro ano de graduação de medicina da FCMSCSP, ao 
longo da disciplina de Ciências Sociais Aplicadas à Saúde, realizaram visitas, junto aos professores da disciplina, preceptores e agentes comunitários de saúde de uma UBS da região central do município de São Paulo, com o objetivo de reconhecer o território de abrangência e as necessidades de saúde da população mediante a realização de entrevistas junto a usuários e famílias.

Após esta primeira etapa de conhecimento do território, os alunos identificaram problemas e situações a fim de realizar uma ação educativa de promoção de saúde e/ou de prevenção junto à comunidade da área de abrangência da UBS. A expressiva vulnerabilidade sócio-econômicoambiental da comunidade e a interface com os riscos de acidentes domésticos, as quais as crianças se encontravam expostas cotidianamente, foram considerados como problemas de grande relevância pelos discentes, sendo escolhido como tema central para o planejamento e execução da atividade educativa de promoção à saúde.

Após a seleção do tema, foi realizado um levantamento bibliográfico voltado a busca de dados epidemiológicos sobre as principais causas de morbimortalidade relacionadas a acidentes na infância, com o intuito de problematizarmos questões consideradas relevantes para a prevenção de tais desfechos. Em parceria com a gerência da UBS, identificamos uma organização não-governamental (ONG) que presta serviços à comunidade local, junto às crianças em situação de vulnerabilidade social, com o objetivo de realizar atividades lúdicas e educativas após o horário da escola. Foi realizada uma primeira visita de reconhecimento do espaço da ONG e das crianças matriculadas com o intuito de discutir junto à coordenação a viabilidade de realização da ação educativa, proposta mediante ao estabelecimento de uma parceria entre a UBS, a ONG e a FCMSCSP.

Para a elaboração das atividades lúdicas os alunos foram divididos em dois grupos: a) Grupo 1 - responsável pela elaboração dos jogos e brincadeiras que envolvessem a temática de prevenção de acidentes na infância, a partir de uma pesquisa de imagens e regras adequadas para as diferentes faixas etárias das crianças matriculadas na ONG; b) Grupo 2 - elaboração de material educativo (utilizando-se de imagens e textos) destinado aos pais e responsáveis com a intenção de fomentar a sensibilização ao tema, junto aos núcleos familiares e demais membros da comunidade.

Os jogos interativos e materiais elaborados pelos alunos foram apresentados aos professores para a realização das devidas adaptações de linguagem para as diferentes faixas etárias. Cabe ressaltar que o referencial teórico utilizado junto aos alunos ao longo deste processo para a elaboração dos jogos lúdicos e dos materiais educativos deveria estimular a reflexão e a problematização de situações vivenciadas pelas crianças em seu cotidiano, assim como deveriam garantir a participação ativa destas. A utilização de metodologias centradas nos interesses e saberes dos participantes, visa potencializar a autonomia e emancipação dos indivíduos, frente a problemas concretos vivenciados no mundo-da-vida destes sujeitos.

Após a realização da ação educativa os alunos escreveram uma narrativa em primeira pessoa, expressando suas percepções acerca da atividade realizada. Para a análise qualitativa das narrativas foram realizadas leitura vertical e horizontal e análise de discurso com criação de domínios de categorias para a interpretação textual ${ }^{9}$.

\section{RESULTADOS}

O processo de elaboração coletiva de uma ação educativa de promoção à saúde relacionada à prevenção de acidentes domésticos na infância culminou com a organização e realização de uma gincana junto às crianças matriculadas na ONG (com faixa etária de 4 a 11 anos) em novembro de 2012. Foram elaborados quatro jogos temáticos produzidos pelos alunos de Medicina da FCMSCSP ao longo da disciplina de Ciências Sociais Aplicadas à Saúde, com base no pensamento de Vygotsky ${ }^{10}$, no qual brincar é o início da vida social do ser humano, sendo uma das principais ferramentas para o desenvolvimento das habilidades das crianças. As brincadeiras a princípio surgem como uma imitação do mundo adulto e de suas regras, entretanto rapidamente tornam-se questionamentos, dando aos participantes a capacidade de interiorizar e reinventar a realidade.

A escolha por brincadeiras populares facilitou a aceitação por parte das crianças por resgatar vivências de seu cotidiano e de potencializar a construção do conhecimento acerca das principais causas de acidentes na infância. Portanto, foram elaboradas quatro estações de brincadeiras, que contavam com três alunos facilitadores e um coordenador geral das atividades (cuja função foi de organizar a transição dos participantes entre uma estação a outra).

A dinâmica geral da gincana consistiu em uma apresentação entre as crianças e alunos (nome e idade), seguida de uma breve explicação do funcionamento de cada jogo. A seguir as crianças eram incentivadas a iniciar a atividade. Após o término de cada brincadeira foi realizada uma conversa na qual as crianças foram informadas a respeito de seu desempenho na atividade e dirigiam-se para a atividade seguinte, onde novamente apreendiam conceitos de prevenção de acidentes a partir da experimentação de uma nova atividade lúdica.

Os jogos elaborados pelos alunos e suas respectivas regras abordaram temas selecionados de acordo com as principais causas de morbimortalidade de acidentes na infância, de maneira que as crianças pudessem entrar em contato com esta temática de forma lúdica e interativa, além de problematizar junto aos alunos facilitadores algumas formas de prevenção de acidentes no ambiente doméstico. Além disso, os jogos constituíram um recurso pedagógico que poderiam ser utilizados em outras oportunidades pelos educadores da ONG em futuras ações junto a comunidade local. 
Os quatro jogos e as regras elaborados pelos alunos de Medicina consistiam em:

a) Jogo da Memória: o jogo era composto por cartas com 10 imagens consideradas de risco para acidente na infância. As cartas ficavam dispostas com as imagens viradas para baixo como em um jogo da memória tradicional. Cada criança poderia virar em cada jogada duas cartas com objetivo de encontrar a mesma imagem com o "sinal de perigo" - um " $X$ " vermelho - em meio às demais. A cada par de cartas encontrado o aluno facilitador problematizava junto ao grupo a percepção dos participantes sobre as imagens buscando associar as imagens a situações vivenciadas pelas crianças em seu cotidiano;

b) Não caia nessa: foram confeccionados quinze cartões ilustrando situações cotidianas que apresentavam (ou não) riscos de queda (Figura 1). Os cartões foram fixados em uma parede de forma que pudessem ser facilmente removidos. As crianças foram divididas aleatoriamente em dois grupos distintos. Os integrantes de cada grupo formaram duas filas a uma distância de aproximadamente dois metros em relação à parede com as imagens. Um dos alunos facilitadores sinalizava o início da brincadeira. Um integrante de cada grupo iniciava uma corrida em direção à parede a fim de pegar duas imagens (uma com risco e uma sem risco de quedas) e depositavam as imagens em dois cestos correspondentes retornando a sua fila e autorizando outro integrante de seu grupo (com um simples toque na mão) a realizar o mesmo procedimento. A brincadeira finaliza-se quando todas as imagens expostas forem retiradas da parede e depositadas nos cestos. Os dois grupos que competiram entre si foram reunidos para a contagem dos pontos em conjunto. Simultaneamente foi realizada uma roda de discussão com a explicação do motivo de determinadas brincadeiras devem ser evitadas e como agir em caso de acidente. Cada figura colocada na caixa certa equivale a 10 pontos. Ganhava o grupo que obtivesse mais pontos;

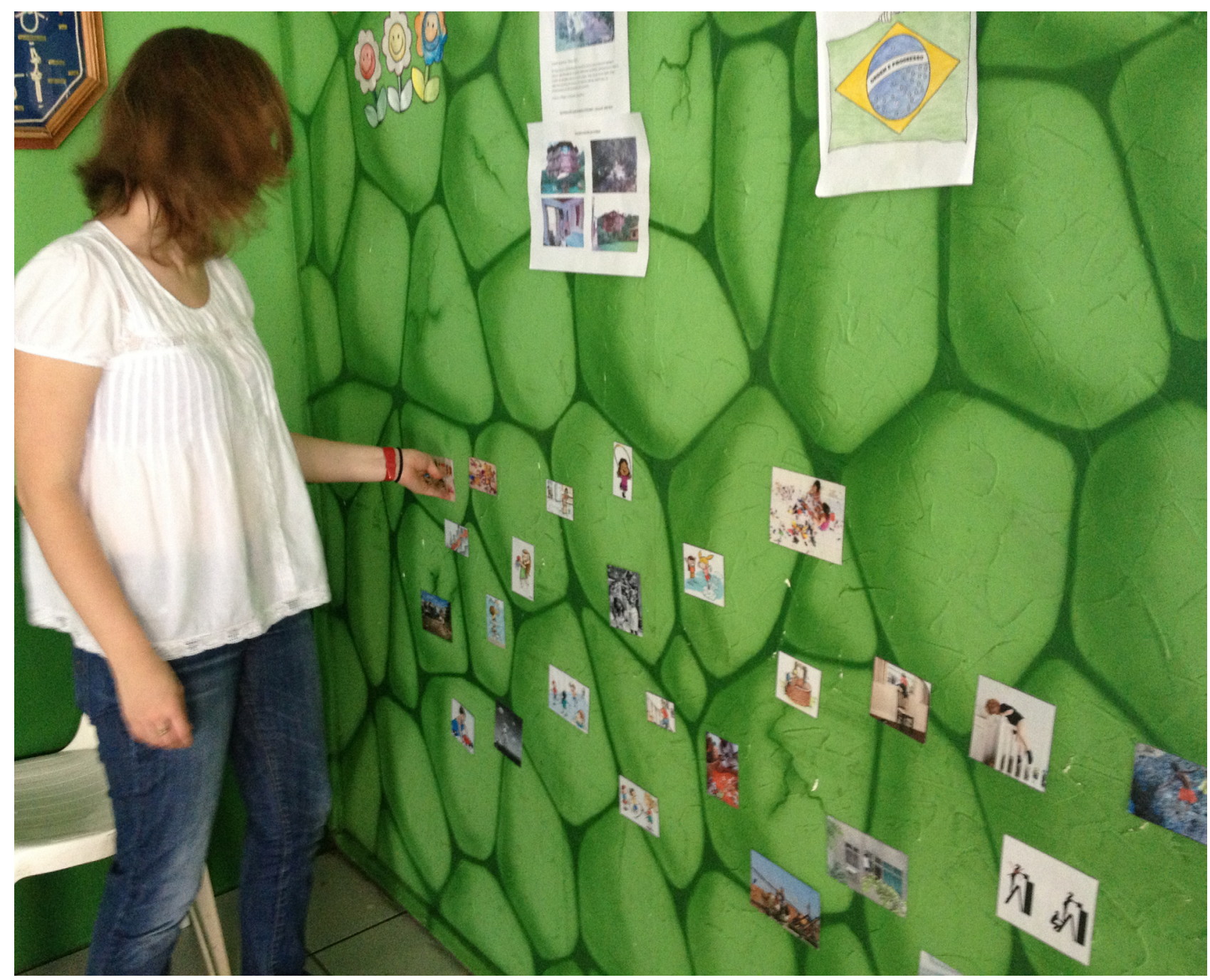


c) Jogo da Associação: o jogo era composto por 34 imagens (Figura 2) dispostas em cima de uma mesa com a face virada para baixo. Para selecionar as equipes cada participante sorteava uma placa com duas cores diferentes (azul e amarelo). Após a composição das equipes os integrantes poderiam selecionar uma das cartas a fim de classificar a imagem como sendo uma situação de risco para acidentes ou isenta de riscos utilizando duas outras imagens (uma carinha sorridente ou uma carinha triste). Os alunos facilitadores discutiram a associação realizada pelos integrantes de cada equipe a partir dos saberes de cada participante;

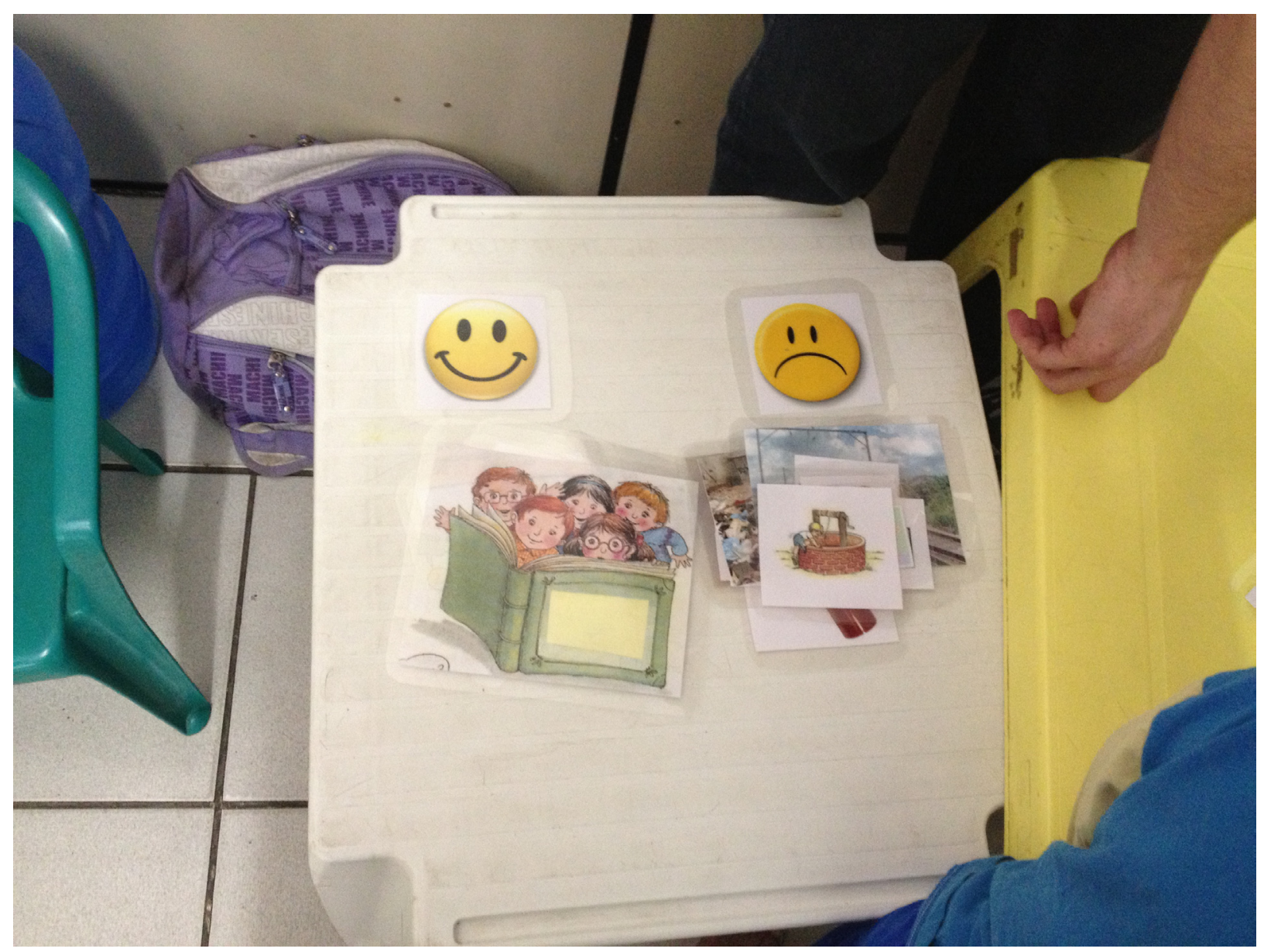

d) "Batata Quente": As crianças foram posicionadas em pé formando uma roda. Uma embalagem vazia de produto de limpeza (e em outros momentos também uma caixa de medicamento) foi entregue a uma das crianças e um dos alunos facilitadores (indicado como mestre da brincadeira) inicia a repetição da frase - "batata quente, quente, quente .... queimou" - quantas vezes desejar. Assim que o mestre iniciar o jogo a embalagem deverá ser passada de mão em mão entre os participantes da roda. A criança que estiver com a embalagem na mão quando a palavra "queimou" for dita pelo mestre deverá sair da roda e dizer se é permitido ou não ingerir produtos de limpeza e/ou medicamento e motivo. A última criança que ficar na roda se torna o mestre e a brincadeira continua.

Após a gincana os alunos organizaram uma roda de conversa junto às crianças a fim de retomar as principais questões discutidas em cada estação de brincadeiras, mostrando algumas imagens e objetos-chave selecionadas previamente e estimulando as crianças a falar sobre o que achavam de maneira que fossem retomados as principais causas de acidentes na infância. As crianças participaram de forma extremamente ativa dos jogos e, na rodada final, mostraram-se interessadas pelo assunto respondendo corretamente as perguntas realizadas pelos alunos facilitadores. Houve supervisão de todas as atividades realizadas pelos alunos por parte dos preceptores e por duas agentes comunitárias da UBS, além dos educadores da ONG.

Ao final da atividade os alunos fizeram a distribuição de prêmios para todos os participantes. Os folhetos explicativos, contendo orientações de fácil compreensão e com o uso de imagens associativas sobre como evitar e prevenir acidentes domésticos (com a adoção de atitudes simples no lar) foram deixados com os profissionais da 
ONG para que fossem entregues aos pais ou responsáveis no horário de encerramento das atividades, como uma estratégia de projeção dessas discussões para os núcleos familiares e demais membros da comunidade.

O folheto explicativo era composto pelos seguintes tópicos: a) Quedas; b) Queimaduras e incêndios; c) Ferimentos por instrumentos pérfuro-cortantes (depositados em acúmulos de lixo nas vias públicas); d) Intoxicações por produtos de limpeza e medicamentos; e) Acidentes fora de casa: um tópico específico para o ambiente da comunidade abrange prevenções de acidentes sobre os trilhos de trem que atravessam o local.

\section{Percepção dos alunos sobre atividade realizada}

A percepção dos alunos em relação à atividade realizada, compreendida mediante a elaboração de uma narrativa em primeira pessoa, apresentou-se de maneira extremamente positiva, tanto para o objetivo da atividade, quanto para a formação dos alunos a partir de uma percepção mais humanística.

"A atividade com as crianças (...) acrescentou tanto
para a formação como aluno de medicina, quanto para
a formação como pessoa. Ter a oportunidade de entrar
em um universo completamente diferente, estudando os
problemas que afetam a comunidade escolhida, foi muito
importante para a maturação das idéias e, consequente-
mente, para o sucesso do projeto" (Aluno 4).

“A criação da intervenção já representou uma grande responsabilidade para o grupo. Todos tinham que estar dispostos para pesquisar, criar, envolver-se para realizar tudo da melhor maneira possível. A realização foi mais fácil do que se imaginava" (Aluno 5).

"O contato direto com essas crianças, com essa comunidade e seus problemas, trouxe uma visão mais humanista para a formação médica" (Aluno 6).

Em relação a percepção dos alunos sobre a interação junto às crianças ao longo da atividade, podemos compreender que as ações educativas baseadas em jogos lúdicos garantiram a participação dos sujeitos a contento.

“as crianças estavam muito receptivas e animadas, aprendiam as brincadeiras com uma facilidade incrível e, mais importante, aprendiam o conteúdo que essas brincadeiras traziam com a mesma facilidade" (Aluno 1).

"Também recebemos bastante carinho e afeto das crianças, construindo uma relação muito confortável e de confiança, fator ainda mais importante para que elas levassem em consideração os ensinamentos que propusemos" (Aluno 6)

"Elas se mostraram atentas às instruções, dispostas e contentes com a atenção recebida" (Aluno 6).
No que tange à percepção sobre a utilização de jogos lúdicos para atividades de promoção à saúde junto às crianças, os alunos compreenderam que este tipo de estratégia configurou-se como adequada e eficiente.

“A criação de brincadeiras demanda uma imersão no universo do público alvo e, portanto, um conhecimento aprofundado do ser em todos os seus aspectos" (Aluno $1)$.

"Com a abordagem feita com jogos, pode-se perceber que a promoção da saúde foi realizada de uma maneira leve, dinâmica e eficiente" (Aluno 1).

Entretanto, ao que se refere à adequação dos jogos elaborados de acordo com a faixa etária, os alunos apontam algumas dificuldades na realização de duas atividades ("Batata quente" e "Jogo da Memória") e ressaltam a importância da adequação de regras das atividades pedagógicas de acordo com a idade dos participantes.

"Algumas atividades mostraram-se inadequadas para o
grau cognitivo das crianças. Na elaboração da brincadeira
preocupou-se mais em encontrar imagens adequadas e
encadear a condução de uma forma que fizesse sentido,
do que em criar estratégias de adaptação para cada faixa
etária contemplada. Assim, algumas atividades podem
ter parecido muito simples para algumas crianças, en-
quanto para outras houve certo grau de dificuldade para
compreender qual o objetivo da atividade em questão"
(Aluno 3).

\section{DISCUSSÃO}

O modelo dominante de educação médica ainda permanece centrado no ensino das doenças, através de aulas teóricas, estratégias de ensino-aprendizagem centrados no professor, com prática predominantemente hospitalar e enfoque no conhecimento técnico-científico. No entanto, este modelo apresenta limitações para atender as necessidades do SUS e vem sofrendo críticas nas últimas décadas. As propostas para um modelo inovador incluem ensino centrado na saúde, com ênfase em ações de promoção à saúde e prevenção de agravos e doenças, com estratégias centradas no aluno, que permitam autonomia na construção do conhecimento, com prática em todos os níveis do sistema de saúde e valorização de atitudes, habilidades, além do conhecimento técnico ${ }^{11}$.

O ensino de promoção à saúde é ainda incipiente nos cursos de graduação de medicina. Os programas indutores de mudanças no ensino médico para formação de médicos que atendam as necessidades da população, como o Programa Nacional de Reorientação da Formação Profissional em Saúde (PRÓ-SAUDE) e o Programa de Educação pelo Trabalho na Saúde (PETSAÚDE), estimulam a realização de ações de promoção à saúde e de prevenção. Estas iniciativas do Ministério da Saúde e do Ministério da Educação buscam "promover transformações no processo de geração de 
conhecimento e prestação de serviços à população para, em função deles, reorientar a formação profissional assegurando uma abordagem integral do processo saúde-doença"12. Os programas corroboram a importância de atender as exigências das DCNs, que visam formar médico com perfil crítico e reflexivo, capaz de atuar em todos níveis do sistema de saúde e que possua a competência de realizar ações de prevenção, promoção, assistência e reabilitação ${ }^{8}$.

Para construção de competências durante o processo de formação de um estudante é essencial integrar o processo ensino-aprendizagem em seus diversos domínios: cognitivo, afetivo e psicomotor. Desta maneira, as experiências práticas do aluno promovem o desenvolvimento das diversas áreas, resultando em aprendizagem significativa. Há evidências de que introduzir experiências práticas na comunidade precocemente na formação do estudante de medicina apresenta resultados positivos, com maior satisfação e interesse do estudante, com aprendizagem de habilidades de comunicação e competências clínicas, além de aumentar aprendizagem sobre o sistema de saúde e ações preventivas ${ }^{13}$. Da mesma forma que é fundamental que o aluno de medicina realize internato, exercendo a profissão sob supervisão, é essencial que o aluno experimente a elaboração e execução de ações de prevenção e promoção, para que esta competência seja realmente adquirida durante a graduação. Para tal, não bastam aulas expositivas, casos clínicos ou simulações. É imperativa a prática, em especial com uso da problematização, como estratégia pedagógica para ensino da promoção à saúde.

A problematização consiste em etapas de observação da realidade, discussão e reflexão sobre problemas encontrados, formalização de pontos-chave para posterior teorização. A partir do estudo, são realizadas hipóteses de solução e elaboração e aplicação de intervenção na realidade ${ }^{14,15}$. Todas as etapas foram cumpridas nesta experiência dos alunos de primeiro ano de medicina da Faculdade de Ciências Médicas da Santa Casa de São Paulo. Os alunos realizaram o reconhecimento do território da unidade básica de saúde e se mobilizaram com diversas questões, entre elas o ambiente arriscado em que muitas crianças brincavam. Participaram de reuniões com a gerência da unidade básica e da organização não-governamental em que atuaram para discussão da pertinência do tema. Escolheram o tema da prevenção de acidentes na infância, buscando informações e artigos a respeito do tema ${ }^{5,6,16,17}$, construindo uma ação de prevenção de acidentes. Articularam, junto aos professores, a ação de prevenção para as crianças e pais, com a elaboração de jogos lúdicos e panfleto informativo. Executaram as oficinas de brincadeiras com as crianças e enviaram folheto explicativo aos pais.

A complexidade da elaboração de uma ação intersetorial é grande no âmbito da saúde. As articulações necessárias, a comunicação e pactuação de um caminho e objetivo em comum entre as instituições e indivíduos são etapas do desenvolvimento de uma ação intersetorial. Requerem habilidades de comunicação, atuação em equipe multiprofissional, liderança e planejamento, sendo que todas estas são com- petências desejadas ao egresso médico, segundo as $\mathrm{DCNs}^{8}$. Existem relatos na literatura de ações incluindo estudantes de medicina com enfoque de prevenção de acidentes na infância ${ }^{18}$. No entanto, há relatos sobre a escassez de ações visando a prevenção de acidentes e violências em crianças e adolescentes ${ }^{19}$, o que justifica a importância deste estudo.

A Política Nacional de Redução da Morbimortalidade por Acidentes e Violências ${ }^{20}$, publicada no ano de 2001, estabelece que "a promoção da saúde deve embasar todos os planos, programas, projetos e atividades da redução da violência e acidentes" e reforça que a prevenção primária deve ser estimulada, fortalecendo os indivíduos para melhorar suas condições de vida e de saúde, ao desenvolver suas aptidões pessoais. A Política Nacional ainda explicita a importância das ações preventivas na Atenção Primária, onde foi realizado o trabalho descrito neste artigo.

A educação em saúde é uma estratégia que busca atingir o empoderamento dos indivíduos, quanto a realização do seu cuidado e a luta por melhorias das suas condições de vida e de saúde. As crianças apresentam potencialidade na atuação de mudanças de estilo de vida. Há experiências quanto a intervenções no campo de alimentação saudável com crianças no meio escolar, sendo inclusive objeto de publicação do Ministério da Saúde em Portugal ${ }^{21}$, que valorizam o saber e o agir da criança, enquanto agente transformador da família.

Há evidências de que intervenções de segurança no ambiente domiciliar são eficientes, principalmente com orientações individualizadas e se necessário com fornecimento de material de segurança ${ }^{22}$. No Brasil, há uma Organização Não-Governamental (ONG) bastante atuante na área da prevenção de acidentes na infância denominada Criança Segura ${ }^{23}$, em que existem dados sobre a prevalência de acidentes na infância no Brasil e que estimula a prevenção destes através da conscientização de pais e filhos. Em todos os tópicos, há abordagem necessária ao adulto que supervisiona a criança, as adaptações a serem feitas no domicílio, carro e mesmo fora do lar e o que deve ser ensinado à criança. Portanto, é bastante claro que as orientações para prevenção de acidentes devem envolver pais e filhos, adultos e crianças na promoção de um futuro seguro.

\section{CONSIDERAÇÕES FINAIS}

O trabalho realizado consistiu em parceria entre universidade, serviço de saúde e ONG com objetivo de realizar ação de empoderamento de crianças e pais na prevenção de acidentes domésticos. Infelizmente, por motivos de escassez recursos humanos, a ação consistiu em prática pontual realizada em uma tarde, com duração de algumas horas. Tais ações são menos efetivas do que aquelas longitudinais, contínuas e integradas a rotina das crianças. No entanto, a possibilidade de discutir o tema e formas de prevenção com cuidadores, crianças e pais pode promover a valorização do tema e incrementar a motivação para mudanças de estilo de vida. 
A experiência pedagógica para os alunos foi reconhecida como promotora de aprendizagem e satisfação. A possibilidade de participar ativamente de seu processo de ensino-aprendizagem foi capaz de motivar os alunos a realizar a intervenção de forma respeitosa e responsável,

Os autores declaram não ter conflitos de interesses.

\section{REFERÊNCIAS}

1. Czeresnia D, Freitas CM, organizadores. Promoção da saúde: conceitos, reflexões, tendências. Rio de Janeiro: Ed. Fiocruz; 2003. p.39-53.

2. Buss PM. Promoção da saúde e qualidade de vida. Cien Saude Coletiva. 2000;5(1):163-77. http://dx.doi. org/10.1590/S1413-81232000000100014

3. Starfield B. Atenção primária: equilíbrio entre necessidades de saúde, serviços e tecnologia. Brasília: UNESCO, Ministério da Saúde; 2002. Disponível em: http://bvsms.saude. gov.br/bvs/publicacoes/atencao_primaria_p1.pdf

4. Brasil. Ministério da Saúde. Departamento de Informática do SUS. Sistema de informação sobre mortalidade [citado 10 dez. 2012]. Disponível em: http://www2.datasus.gov.br/ DATASUS/index.php?area $=0205$.

5. Del Ciampo LA, Ricco RG. Acidentes na infância. Pediatria (São Paulo). 1996;18(4):193-7. Disponível em: http://www. pediatriasaopaulo.usp.br/upload/pdf/245.pdf

6. Unglert CVS, Siqueira AAF, Carvalho GA. Características epidemiológicas dos acidentes na infância. Rev Saude Publica. 1987;21:234-45. Disponível em: http://www.scielo. br/pdf/rsp/v21n3/08.pdf

7. Buss PM. Promoção da saúde na infância e adolescência. Rev Bras Saude Mater Infant. 2001;1(3):279-82. http:// dx.doi.org/10.1590/S1519-38292001000300010

8. Brasil. Ministério da Educação. Conselho Nacional de Educação. Câmara de Educação Superior. Resolução n.4, CNE/CES de 07 de novembro de 2001. Institui diretrizes curriculares nacionais do curso de graduação de medicina. Diário Oficial da União, Brasília, DF. 9 nov. 2001; Seção 1, p.38. Disponível em: http://portal.mec.gov.br/cne/arquivos/ pdf/CES04.pdf

9. Minayo MC. O desafio do conhecimento: pesquisa qualitativa em saúde. São Paulo: Hucitec, Abrasco; 1992. http://dx.doi.org/10.1590/S0102-311X1992000300013

10. Drago R, Rodrigues PS. Contribuições de Vygotsky para o desenvolvimento da criança no processo educativo: algumas reflexões. Rev FACEVV (Vila Velha). 2009;3:4956. Disponível em: http://www.facevv.edu.br/Revista/03/ ARTIGO\%20ROGERIO\%20DRAGO.pdf

11. Lampert JB. Tendências de mudanças na formação médica no Brasil: tipologia das escolas. 2a ed. São Paulo: Hucitec, Associação Brasileira de Educação Médica; 2009.

12. Campos FE, Haddad AE, Pierantoni CR, Brenelli SL, Cury GC, Morita MC, Passarella T. O Programa Nacional de Reorientação da Formação Profissional em Saúde: o Pró-Saúde. In: Pierantoni CR, Viana ALD, organizadores. Educação \& saúde. São Paulo: Hucitec; 2010. tanto na elaboração do projeto, como na aplicação deste. $\mathrm{O}$ uso da problematização enquanto ferramenta pedagógica parece ter sido acertada no ensino de promoção à saúde e prevenção de acidentes na infância.
13. Dornan T, Litllewood S, Margolis S, Scherpbier A, Spencer J, Ypinazar V. How can experience in clinical and community settings contribute to early medical education? A BEME systematic review. Med Teach. 2006;28(1):3-18. doi:10.1080/01421590500410971

14. Berbel NAN. A problematização e a aprendizagem baseada em problemas: diferentes termos ou diferentes caminhos? Interface Comun Saude Educ. 1998;2(2):139-54. http:// dx.doi.org/10.1590/S1414-32831998000100008.

15. Cyrino EG, Toralles-Pereira ML. Trabalhando com estratégias de ensino-aprendizagem por descobertas na área da saúde: a problematização e a aprendizagem baseada em problemas. Cad Saude Publica. 2004;20(3):780-8. Disponível em: http://www.scielo.br/pdf/csp/v20n3/15

16. Ramos CLJ, Targa MBM, Stein AT. Perfil de intoxicações na infância atendidas pelo centro de informações toxicológicas do Rio Grande do Sul (CIT/RS), Brasil. Cad Saude Publica. 2005;21(4):1134-41. Disponível em: http://www.scielo.br/ $\mathrm{pdf} / \mathrm{csp} / \mathrm{v} 21 \mathrm{n} 4 / 15 . \mathrm{pdf}$

17. Martins CBG. Acidentes na infância e adolescência: uma revisão bibliográfica. Rev Bras Enf. 2006;59(3):344-8. http://dx.doi.org/10.1590/S0034-71672006000300017

18. Ribeiro BB, Eckert JB, Figueiredo ACM, Galhardi WMP, Campanaro CM. Experiência de ensino em medicina e enfermagem: promovendo a saúde da criança. Rev Bras Educ Med. 2012;36(1 Supl. 2):85-96. Disponível em: http:// www.scielo.br/pdf/rbem/v36n1s2/a14v36n1s2.pdf

19. Pordeus AMJ, Fraga MNO, Facó TPP. Ações de prevenção dos acidentes e violências em crianças e adolescentes, desenvolvidas pelo setor público de saúde de Fortaleza, Ceará, Brasil. Cad Saude Publica. 2003;19(4):1201-4. Disponível em: http://www.scielo.br/pdf/csp/v19n4/16868.pdf

20. Brasil. Ministério da Saúde. Política nacional da redução da morbimortalidade por acidentes e violências. Portaria GM/ MS no 737 de 16/05/01. Diário Oficial da União, Brasília, DF, n. 96, 18 maio 2001. Seção 1e. Disponível em: http:// bvsms.saude.gov.br/bvs/publicacoes/acidentes.pdf

21. Portugal. Ministério da Educação. Educação alimentar em meio escolar: referencial para uma oferta alimentar saudável. Lisboa: Ministério da Educação; 2006. Disponível em: http://www.educacao.cm-oeiras.pt/SiteCollectionDocuments/Livro-educacao-alimentar_meio_escolar.pdf

22. Kendrick D, Young B, Mason-Jones AJ, Ilyas N, Achana FA, Cooper NJ, et al. Home safety education and provision of safety equipment for injury prevention. Cochrane Library. 2012;9:1-176. DOI: 10.1002/14651858.CD005014.pub2

23. ONG Criança Segura [citado 14 abr. 2013]. Disponível em: http://www.criancasegura.org.br. 